not, in 1934, "President of the Swann galleries." He was, at that time, a bookseller and the Swann galleries, with which he never had any connection, was not in existence. These are minor blemishes on an interesting contribution.-David A. Randall, The Lilly Library, Indiana University.

\section{An Introduction to Scientific Research in} Librarianship. By Herbert Goldhor. Final Report, Project No. 7-1271, Contract No. OEC-1-7-071217-5113. U.S. Department of Health, Education and Welfare, Office of Education, Bureau of Research. Distributed by Illini Union Bookstore.

This brief survey of research methods is designed for doctoral students in librarianship and for practicing librarians who would like to become more critical consumers of research. Dr. Goldhor begins with a discussion of the basic approaches to knowledge and truth, and proceeds to describe and evaluate the methods used in the approach which he defines as scientific research. The fulfillment of such a broad assignment in the space of 201 pages results in exactly that which is suggested by the title-an introduction. This is neither a textbook nor a manual, but an exposition for the beginner on the meaning, goals, and limitations of scientific research in librarianship.

With topics ranging from historical research to statistical inference, the treatment is much too general to aid the student in developing practical methodological or critical skills. Dr. Goldhor's book rather serves to point out the techniques which the student should master in order to become an accomplished researcher. It also aims at developing a realistic attitude towards research, including an understanding that awesome patience is required to perform it properly, and an appreciation of the fact that no single study is likely to resolve any significant research question. While there are some solid guidelines on how to identify a researchable topic and how to approach the planning and design of a study, the serious student would need to go beyond Goldhor to the more detailed and technical works listed in his bibliographies. For a general text, this reviewer's preference is Fred Kerlinger's Foundations of Behavioral Research.

There are several notable and welcome emphases in Goldhor's work. Planning and design of the research study is given equal treatment with data collection and analysis. Hypothesis testing is emphasized. While Goldhor's idealistic description of a hypothesis as a statement of relationship which is "universal, invariant and causal" will find only rare application in librarianship, the use of less ambitious hypotheses as focusing devices would improve many studies in librarianship. The frequent lack of a formal hypothesis statement in library research is related to the widespread use of inadequate designs.

Goldhor also emphasizes theory-oriented research. The development of theory is necessary to amend perhaps the major deficiency of library research in general, the fact that ". . . most library research consists of single studies whose results are not cumulative." If a unified, cumulative research effort is to be sustained in any area of librarianship, it will occur only when some form of theory, good or bad, has been posited. For that reason Goldhor's emphasis on a theoretical orientation is precisely what is needed at this point. It serves as another reminder that research in librarianship still has a long way to go. -Joe Hewitt, University of Colorado.

Magazines for Millions: The Story of Specialized Publications. By James L. C. Ford. Carbondale, Ill.: Southern Illinois University Press, 1969. 320p. \$11.75. (79-76187).

There is much in this book which will be of interest to librarians working with serials and to students and faculty in journalism and communications as well as to the lay reader concerning specialized magazines. It is a comprehensive study of the multimillion dollar business of publishing journals aimed toward the special interests of millions of readers. Mr. Ford's work is well organized and very readable -a difficult feat to accomplish as this type of material could easily end up in a form of bibliographic cataloging interspersed with statistics. Much of the information was 